\title{
Prediction of surface topography in precision hard machining based on modelling of the generation mechanisms resulting from a variable feed rate
}

\author{
W. Grzesik ${ }^{1}$
}

Received: 10 May 2017 / Accepted: 13 September 2017 / Published online: 29 September 2017

(C) The Author(s) 2017. This article is an open access publication

\begin{abstract}
The paper presents an original contribution to the prediction of surface topography produced by precision hard turning operations using CBN cutting tools and the variable feed rate of $0.025-0.075 \mathrm{~mm} / \mathrm{rev}$. The differences between theoretical and real surface roughness parameters $R z$ and $S z$ are quantified in terms of springback effect, additional smoothing of irregularities and side flow effect. The primary experimental study includes measurements of 2D and 3D surface roughness parameters using contact profilometer. Correspondingly, cutting forces were measured using a piezoelectric dynamometer, and based on this data, specific corresponding values of ploughing energy and friction coefficient were determined. It was found that the measured value of maximum height of the surface $S z$ differs from the theoretical value mainly due to elastic recovery of the machined surface and the smoothing effect at the lower feeds and the elastic recovery and the side flow effect at the higher feeds employed. An empirical model for the prediction of the $\mathrm{Sz}$ value in function of the feed rate is derived. The prediction accuracy can be improved by advanced numerical modelling of surface generation mechanisms and associated distortions.
\end{abstract}

Keywords Hard turning · Friction · Springback effect · Side flow effect $\cdot$ Surface roughness

W. Grzesik

w.grzesik@po.opole.pl

1 Faculty of Mechanical Engineering, Opole University of Technology, 45-271 Opole, Poland

\section{Introduction}

Hard machining has been established as a leading machining technology for various machine components made of highstrength steels with surface finish comparable to grinding effects [1]. Predominantly, scientific and engineering issues of hard turning do not address sufficiently surface topography and surface assessment is narrowed to the $R a$ or $R z$ roughness parameters $[1,2]$. In addition, the distortion of surface topography in finish hard machining has not been investigated satisfactorily. It should be noted that surface generation mechanisms developed for machining of materials of low and medium hardness cannot be applied for hard materials. This is due to the fact that strong adhesive interaction between the chip and the tool material characteristic for severe plastic deformation does not occur in hard machining [1]. The molecularmechanical theory of friction was applied for predicting the transition from interfacial sliding to micro-cutting when turning AISI 1045 steel with P10 carbide cutting tools [3]. Instead, intensive ploughing action of the cutting edge and resulting elastic recovery of the hard-machined layer are predominantly observed when removing material using CBN cutting tools with high negative rake angles. It is evident to incorporate the specific influence of the mechanics of the chip formation and the tool wear in the formation of the machined surface and subsurface layer. It was revealed [4] that in ultraprecision hard turning, the generation of surface roughness is limited by such factors as tool cutting edge defects, cutting vibration and elastic and plastic deformation of the workpiece material. Plastic deformation becomes an important component when the feed decreases down to $0.02 \mathrm{~mm} / \mathrm{rev}(20 \mu \mathrm{m} / \mathrm{rev})$ (percentage about 90\%). Moreover [5], the relation between measured and theoretical values of $\mathrm{P}-\mathrm{V}(R z)$ parameter for turning and facing of aluminium with cemented carbide and PCD tools suggests that the $R z$ values down to 0.02 times the insert edge 
radii are possible. Modelling of material side flow for CBN tools in hard turning of AISI 52100 bearing steel with variable feed rate $(f=0.1,0.2$ and $0.4 \mathrm{~mm} / \mathrm{rev})$ and nose radius $\left(r_{\varepsilon}=0.4,1.2,1.6\right.$ and $\left.3.4 \mathrm{~mm}\right)$ indicated that it increases from about $1 \mu \mathrm{m}$ up to about $12 \mu \mathrm{m}$ for the tool nose radius $r_{\varepsilon}=0.4$ and $3.4 \mathrm{~mm}$, respectively [6]. The side flow effect was also investigated along with 3D surface topography for high-speed hard turning of a bearing steel of $60 \pm 2 \mathrm{HRC}$ with the cutting speed of 100-300 $\mathrm{m} / \mathrm{min}$ and feed rate of 0.05 and $0.1 \mathrm{~mm} / \mathrm{rev}$ [7]. It is reasoned that $3 \mathrm{D}$ roughness parameters better characterize the deterioration of the machined surface due to flank wear and side flow is intensified at higher speeds. Similarly, the springback effect (elastic recovery) was predicted under variable cutting speed of 10-450 $\mathrm{m} / \mathrm{min}$ using FEM for aluminium and titanium [8]. For instance, it increases from about 3 up to $10 \mu \mathrm{m}$ for Ti6Al4V alloy when cutting speed increases from 10 to $100 \mathrm{~m} / \mathrm{min}$. A high coherence between $R a$ parameter and the springback was found.

The prediction of the surface roughness produced by machining operations is based on the machining theory, experimental investigations, designed experiments, artificial intelligence (AI) and multi-scale analysis $[9,10]$. Geometrical, physical, empirical and simulation models are the mostly used ones $[2,9]$. In empirical models, the most important variables are the feed rate, the tool corner radius, the depth of cut and the cutting speed in that order. The practical value of empirical models is substantially limited to the set of variable factors selected by manufacturers and, as a result, they used simple theoretical formulas for both $R a$ and $R z$ roughness parameters and compare them with measured values [2]. The main drawback of such approach was that all associated effects leading to the distortion of surface topography (for instance Brammertz's model represented by Eq. 8) are considered individually. The author's analysis suggests that they occur together and their intensity depends on the cutting parameters and the real geometry of cutting tools used. The main advantage of this study is that several factors such as ploughing action of the cutting edge, elastic recovery, smoothing effect of the increased irregularities and unremoved material on the surface were considered comprehensively in precision hard turning (PHT) with variable feed of $0.025-0.075(0.1) \mathrm{mm} / \mathrm{rev}$ using chamfered CBN tools. The selection of the feed rate lower than $0.1 \mathrm{~mm} / \mathrm{rev}$ results from the fact that its increase above $0.1 \mathrm{~mm} / \mathrm{rev}$ causes a rapid increase of the $R a$ roughness parameter [11].

\section{Measurements and computations of process data}

\subsection{Measurements of cutting forces and specific energies}

Measurements of three components of the resultant cutting force $\left(F_{\mathrm{c}}, F_{\mathrm{f}}\right.$ and $\left.F_{\mathrm{p}}\right)$ were performed in the $x y z$ coordinate system as shown in Fig. 1a. These three cutting forces were transformed into the $l_{\mathrm{mn}}$ coordinate system (Fig. $1 \mathrm{~b}$ ) using two transformation matrixes given by Eq. 1 [12] in order to determine the friction coefficient for the rake face. The geometrical details of the machined layer generated by means of rounded nose inserts is shown in Fig. 1a.

According to Fig. 1, the $l_{\mathrm{mn}}$ system is obtained by rotating the $x y z$ system by the inclination angle $\lambda_{\mathrm{s}}$ around the $x$-axis and by the normal rake angle $\gamma_{\mathrm{n}}$ around the $y$-axis. The product of relevant transformation matrixes $[\mathrm{TM}]_{\mathrm{x}}$ and $[\mathrm{TM}]_{\mathrm{y}}$ is defined by Eq. 1 .

$$
\begin{aligned}
{[T M] } & =[T M]_{x}[T M]_{\mathrm{y}} \\
& =\left[\begin{array}{ccc}
1 & 0 & 0 \\
0 & \cos \lambda_{s} & -\sin \lambda_{\mathrm{s}} \\
0 & \sin \lambda_{s} & \cos \lambda_{\mathrm{s}}
\end{array}\right]\left[\begin{array}{ccc}
\cos \gamma_{n} & 0 & -\sin \gamma_{n} \\
0 & 1 & 0 \\
\sin \gamma_{n} & 0 & \cos \gamma_{n}
\end{array}\right] \\
& =\left[\begin{array}{ccc}
\cos \gamma_{n} & 0 & -\sin \gamma_{\mathrm{n}} \\
-\sin \lambda_{\mathrm{s}} \sin \gamma_{\mathrm{n}} & \cos \lambda_{\mathrm{s}} & -\sin \lambda_{\mathrm{s}} \cos \gamma_{n} \\
\cos \lambda_{s} \sin \gamma_{o} & \sin \lambda_{s} & \cos \lambda_{\mathrm{s}} \cos \gamma_{n}
\end{array}\right]
\end{aligned}
$$

Hence, the transformation of force components from the $x y z$ coordinate system to the $l_{\mathrm{mn}}$ system using the matrix [TM] is given by Eq. 2 .

$$
\left[\begin{array}{l}
F_{\mathrm{n}} \\
F_{1} \\
F_{m}
\end{array}\right]=[T M]\left[\begin{array}{l}
F_{\mathrm{x}} \\
F_{\mathrm{y}} \\
F_{\mathrm{z}}
\end{array}\right]
$$

By multiplying symmetrical $3 \times 3$ matrix (Eq. 1) and column matrix in Eq. 2, one obtains three equations for determining $F_{1}, F_{\mathrm{m}}$ and $F_{\mathrm{n}}$ forces in terms of the measured $F_{\mathrm{x}}, F_{\mathrm{y}}$ and $F_{\mathrm{Z}}$ forces. They are as follows:

$$
\begin{aligned}
& F_{1}=-F_{\mathrm{x}} \sin \lambda_{\mathrm{s}} \sin \gamma_{n}+F_{y} \cos \lambda_{\mathrm{s}}-F_{\mathrm{z}} \sin \lambda_{\mathrm{s}} \cos \gamma_{\mathrm{n}} \\
& F_{m}=F_{\mathrm{x}} \cos \lambda_{s} \sin \gamma_{\mathrm{n}}+F_{\mathrm{y}} \sin \lambda_{\mathrm{s}}+F_{\mathrm{z}} \cos \lambda_{s} \cos \gamma_{\mathrm{n}} \\
& F_{\mathrm{n}}=F_{x} \cos \gamma_{\mathrm{n}}-F_{\mathrm{z}} \sin \gamma_{\mathrm{n}}
\end{aligned}
$$

Specific cutting $k_{\mathrm{c}}$ and ploughing $k_{\mathrm{p}}$ pressures are calculated based on the equivalent cutting edge of the length $l_{\mathrm{k}}$ and the mean uncut thickness (UCT) $h_{\mathrm{m}}$ shown in Fig. 1 a. Hence:

$$
\begin{aligned}
& k_{\mathrm{c}}=F_{\mathrm{c}} / A_{c} \\
& k_{p}=F_{p} / A_{\mathrm{c}}
\end{aligned}
$$

where the cross-sectional area of cut $A_{\mathrm{c}}=h_{\mathrm{m}} \times l_{\mathrm{k}}$.

Values of the specific cutting $e_{\mathrm{c}}$ and ploughing $e_{\mathrm{p}}$ energies are determined by the transformation of units from N/mm $\left(10^{6} \times \mathrm{N} / \mathrm{m}^{2}\right)$ to $10^{6} \times \mathrm{N} \times \mathrm{m} / \mathrm{m}^{2} \times \mathrm{m}=\mathrm{MJ} / \mathrm{m}^{3}$. Finally, the unit of the specific cutting energy was $\mathrm{GJ} / \mathrm{m}^{3}\left(10^{3} \times \mathrm{MJ} / \mathrm{m}^{3}\right)$. 


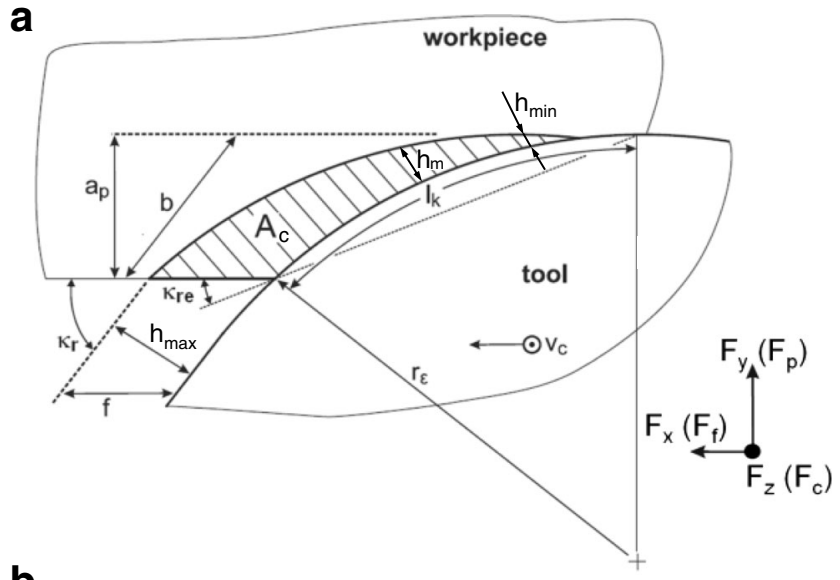

b

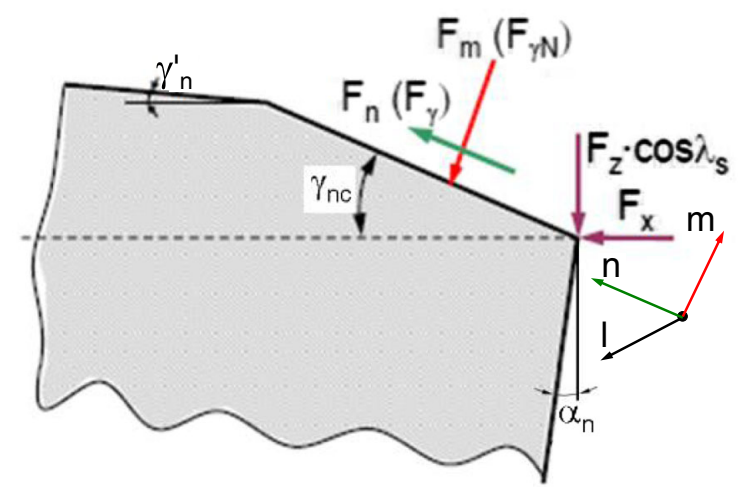

Fig. 1 Dimensioning of uncut chip (a) and resolution of resultant cutting force in $l_{\mathrm{mn}}$ coordinate system (b) $[12,13]$

\subsection{Measurements of surface roughness parameters}

Surface topographies generated by CBN tools were measured by means of the stylus contact method using a TOPO-01P contact profilometer and three non-contact methods: confocal, white-light scanning interferometer and optical with focus variation using versatile S-lynx 3D profiler by Sensofar Metrology, because the contact profilometer is not equipped with the function of precise contour shape measurement. The approximation of the cutting edge radius was performed automatically using a set of reference circles.

$3 \mathrm{D}$ roughness parameters were determined according to ISO 25178 standard, and surface topographies were visualized using a Digital Surf, Mountains ${ }^{\circledR}$ Map package. They include $\mathrm{S}$ and V standardized ISO texture parameters [14]. The definitions, practical interpretations and measurements of 3D surface roughness parameters termed "areal surface texture" are presented by Leach [15]. The choice of the measurement (profiling) technique (stylus profilometer versus laser profilometer or atomic force microscope) depends on the scale of the surface roughness, i.e. from micro- to nano-scale [10, 14]. In this investigation, height parameters were analyzed in comparison to their computed values with a different scale of distortion shown in Fig. 4. In particular, a special searching algorithm which allows the selection of minimum and maximum values of $R z(R t)$ parameter from 2,3 or 10 surface profiles was implemented in order to consider the scattering of the measured data (see Fig. 5).

\subsection{Computations of friction coefficient and elastic recovery}

The friction coefficient for the rake face-chip contact can be determined as the ratio of the $F_{\mathrm{n}}$ (Eq. 3.3) and the $F_{\underline{m}}$ (Eq. 3.2) forces as follows:

$\mu_{\gamma}=\frac{F_{n}}{F_{m}}=\frac{F_{\gamma}}{F_{\gamma N}}$

where $F_{\gamma}$ is the friction force and $F_{\gamma \mathrm{N}}$ is the normal force on the rake face (Fig. 1b).

The elastic recovery of the machined surface corresponding to friction at the tool-chip interface defined by Eq. 5 is determined using the following equation $[16,17]$ :

$\delta_{\mathrm{s}}=r_{\mathrm{n}}\left(1-\frac{1+\mu_{\gamma}}{\sqrt{2\left(1+\mu_{\gamma}^{2}\right)}}\right)$

where $r_{\mathrm{n}}$ is the measured cutting edge radius (Fig. 3b) and $\mu_{\gamma}$ is the friction coefficient on the rake face.

Equation (6) was derived based on the theory of elasticity applied to the case when an indenter of $r_{\mathrm{n}}$ radius loads an elastic half-space with defined friction coefficient [17, 18]. For this reason, the cutting edge radius was measured precisely (Fig. 3a) to determine accurate values of the elastic recovery (see Appendix Table 1).

Figure 2 shows that elastic recovery of the machined surface changes practically linearly with both the ploughing energy and friction coefficient $\mu_{\gamma}$. It should be noted that PHT with the minimum feed of $0.025 \mathrm{~mm} / \mathrm{rev}$ corresponds with the highest value of the friction coefficient equal to 2.5 and the specific ploughing energy of $43.1 \mathrm{GJ} / \mathrm{m}^{3}$. In comparison, the corresponding value of the specific cutting energy in this case is equal to $17.6 \mathrm{GJ} / \mathrm{m}^{3}$ which is in accordance with metal-cutting data $[13,19]$.

\subsection{Computations of heights and smoothing rate of irregularities}

The theoretical values of roughness height were determined using both the classical circle models (Eq. 7), expressing its correlation with the feed and the corner radius and more advanced elliptical model (known as the Brammertz's formula) which additionally considers the minimum UCT ( $h_{\min }$ in Eq. 8) and in consequence a small unremoved area of the rough surface. 


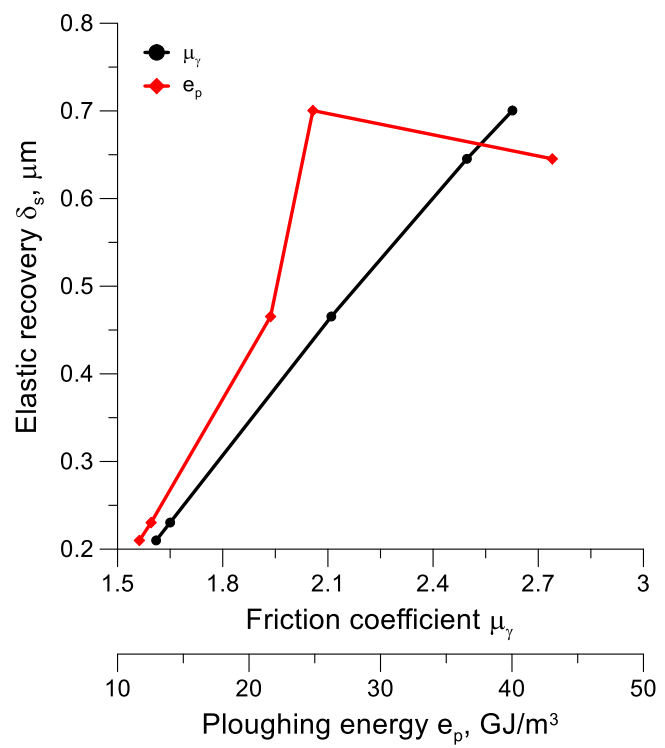

Fig. 2 Correlations between elastic recovery and ploughing energy and friction coefficient at the rake face

$R z t=\frac{f^{2}}{8 r_{\varepsilon}}$

$R z t^{B}=\frac{f^{2}}{8 r_{\varepsilon}}+\frac{h_{\min }}{2}\left(1+\frac{r_{\varepsilon} h_{\min }}{2}\right)$

In this study, the smoothing effect resulting from the additional cut of irregularities during subsequent revolutions of the workpiece after their elastic recovery was taken into consideration. The appropriate formulas are as follows[19, 20]:

$R t_{\mathrm{sm}}=\frac{5 f^{2}}{8 r_{\varepsilon}}+\frac{h_{\min }}{2}\left(\frac{r_{\varepsilon} h_{\min }}{f^{2}}-1\right)$

$R t_{\mathrm{sm}}^{\prime}=\frac{4 f^{2}}{8 r_{\varepsilon}}+\frac{h_{\min }}{2}\left(1+\frac{r_{\varepsilon} h_{\min }}{4 f^{2}}\right)$

Equation 9a represents the case when the individual irregularity is re-generated after smoothing and Eq. $9 \mathrm{~b}$ expresses the smoothing effect occurring in the second revolution of the workpiece. The second case takes place when the feed $f \leq$ $\sqrt{r_{\varepsilon} h_{\min }}$ (for $r_{\varepsilon}=0.8 \mathrm{~mm}$ and $h_{\min }=0.8 \mu \mathrm{m}, f \leq 0.08 \mathrm{~mm} /$ rev). Equations $9 \mathrm{a}$ and $9 \mathrm{~b}$ were derived by adding the first correction terms to Brammertz's formula given by Eq. 8 [20].

\section{Experimental details}

\subsection{Workpiece material and cutting tool}

The workpiece material was a $41 \mathrm{Cr} 4$ (AISI 5140 equivalent) alloy steel with Rockwell's hardness of $57 \pm 1 \mathrm{HRC}$ and initial $S a$ roughness of about $0.4 \mu \mathrm{m}$. In order to determine an accurate value of the minimum UCT, the cutting edge radius was determined using $3 \mathrm{D}$ image obtained on a focus variation microscope as shown in Fig. 3. It varies slightly in the range of 8-10 $\mu \mathrm{m}$ and, in consequence, computations for the elastic recovery (Eq. 6) were carried out assuming its lower and upper values of 8 and $10 \mu \mathrm{m}$. In Fig. $3 \mathrm{~b}$, a small land $b_{\alpha} \approx 6 \mu \mathrm{m}$ can be noticed, so the smoothing effect can be expected as well. According to the well-established relation between the minimum UCT and the cutting edge radius, it was assumed that the ratio $h_{\min }=0.1 r_{\mathrm{n}}[3,16,19]$.

\subsection{Hard turning conditions}

Turning operations were performed on a CNC turning center, Okuma Genos L200E-M with an installed three-component Kistler dynamometer (model 9129A) and consumed energyrecording system. The resultant cutting force was resolved into three components $-F_{\mathrm{c}}, F_{\mathrm{f}}$ and $F_{\mathrm{p}}$. The measured signals were processed with a sampling rate of $f=1 \mathrm{kHz}$ and a lowpass filter with a cut-off frequency of $f_{\mathrm{c}}=300 \mathrm{~Hz}$.

Initial finish hard turning (FHT) was performed with $v_{\mathrm{c}}=150 \mathrm{~m} / \mathrm{min}, f=0.1 \mathrm{~mm} / \mathrm{rev}, a_{\mathrm{p}}=0.15 \mathrm{~mm}$ and subsequent precision hard turning (PHT) operations with the same cutting speed but variable feed rate of $0.025,0.035,0.050,0.060$ and $0.075 \mathrm{~mm} / \mathrm{rev}$, respectively. CBN TNGA $160408 \mathrm{~S} 01030$ chamfered inserts with electro-erosion (ER) honed cutting edges. Typically, the cutting edge is prepared by sinking it into a counterface [21]. This special preparation technology allows to produce cutting edges with the minimum radius of about $5 \mu \mathrm{m}$. The cutting edge radius of $r_{\mathrm{n}}=8-10 \mu \mathrm{m}$ and chamfer width $b_{\gamma} \approx 100 \mu \mathrm{m}$ were measured (see Fig. $3 \mathrm{~b}$ ). The cutting tool angles in the tool-in-hand system were the following: $\kappa_{\mathrm{r}}=91^{\circ}, \lambda_{\mathrm{s}}=-6^{\circ}, \gamma_{\mathrm{nc}}=-30^{\circ}, \gamma_{\mathrm{n}}=-6^{\circ}$.

\section{Experimental results and discussion}

\subsection{Factors influencing surface roughness in PHM}

As pointed out in Section 1, surface generation in precision hard turning (PHT) is influenced by several distortion effects depending on the feed rate applied. They include such effects as elastic recovery caused by intensive ploughing action of the cutting edge, smoothing effect of the irregularities in subsequent revolutions and plastic side flow due to the lateral flow of the thermally softened material.

Values of measured and computed surface roughness parameters presented graphically in Fig. 4 are specified in Appendix Table 2.

In this study, all surface distortion effects are related to the maximum surface height $S z$ (surface topography) and corresponding $2 \mathrm{D}$ parameter $R z$ (surface profile). 
Fig. 3 Stereometric image of the cutting edge (a) and its dimensioning (b) at magnification $\times 200$
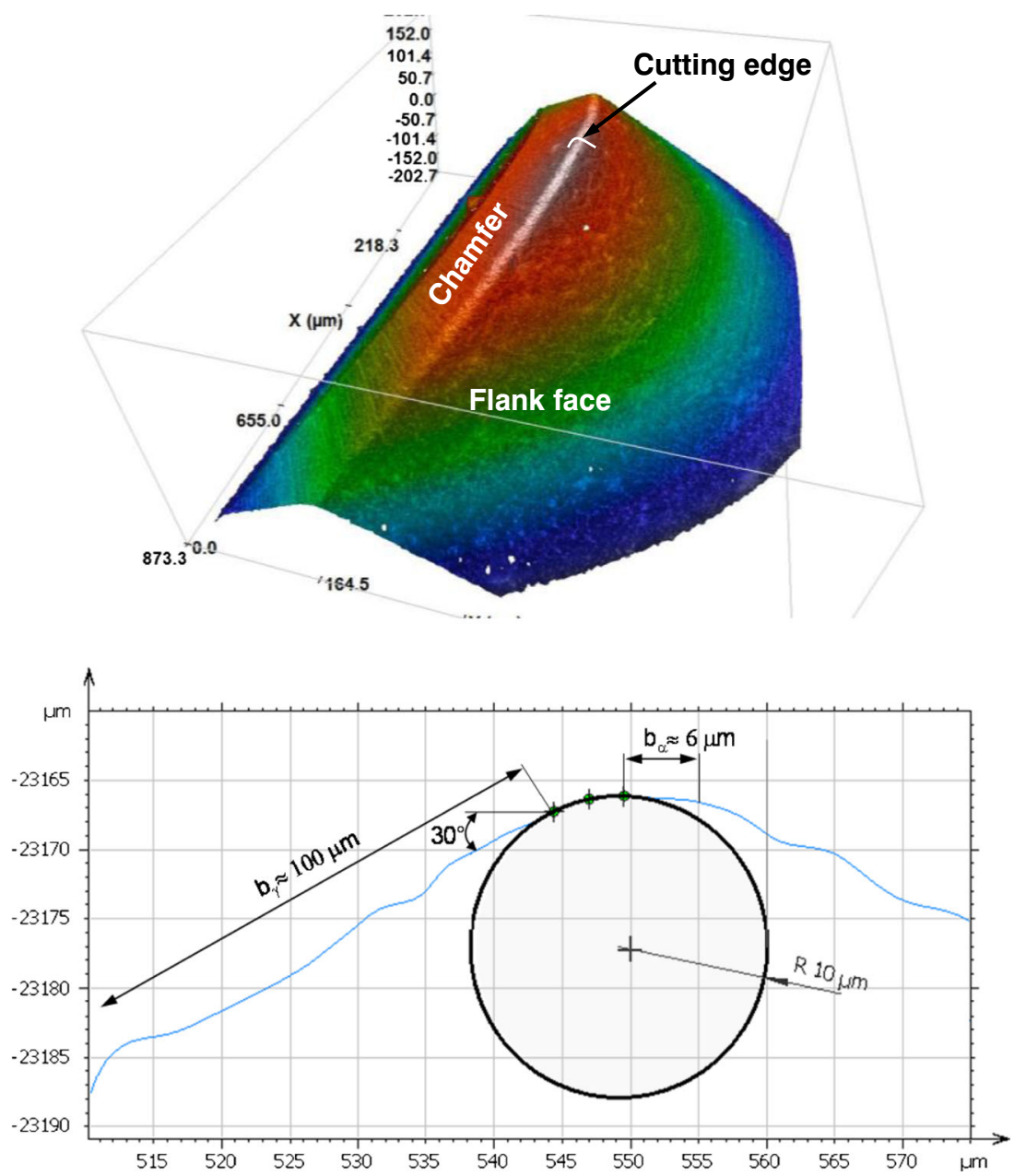

According to Fig. 4, the elastic recovery modelled by Eq. 6 (curves \#3a and 3b) was established to be mostly predominant at the minimum feeds of 0.025 and $0.035 \mathrm{~mm} / \mathrm{rev}$. This corresponds well with the Brammertz's model represented by curves \#2a and $2 \mathrm{~b}$. It should be noted that springback effect seems to be important also when PHT with the feed rate higher than $0.06 \mathrm{~mm} / \mathrm{rev}$. The smoothing effect occurs simultaneously with the previous one and exists also at a higher feed up to about $0.05 \mathrm{~mm} / \mathrm{rev}$. When the feed exceeds $0.05 \mathrm{~mm} / \mathrm{rev}$, the Brammertz's model (Eq. 7) fits the measured $S z$ values better than the elastic recovery because it decreases as shown in Fig. 2. Finally, at the feeds between 0.075 and $0.1 \mathrm{~mm} / \mathrm{rev}$, surface profiles become more regular with a visible plastic flow effect at the highest feed (Fig. 6c, d). This observation is in a strong agreement with previous reports by Kishawy et al. [6]. All these influences were documented quantitatively by the introduction of appropriate analytical models.

In particular, in PHT the minimum value of $R z$ parameter is predicted with sufficient accuracy using theoretical formula,

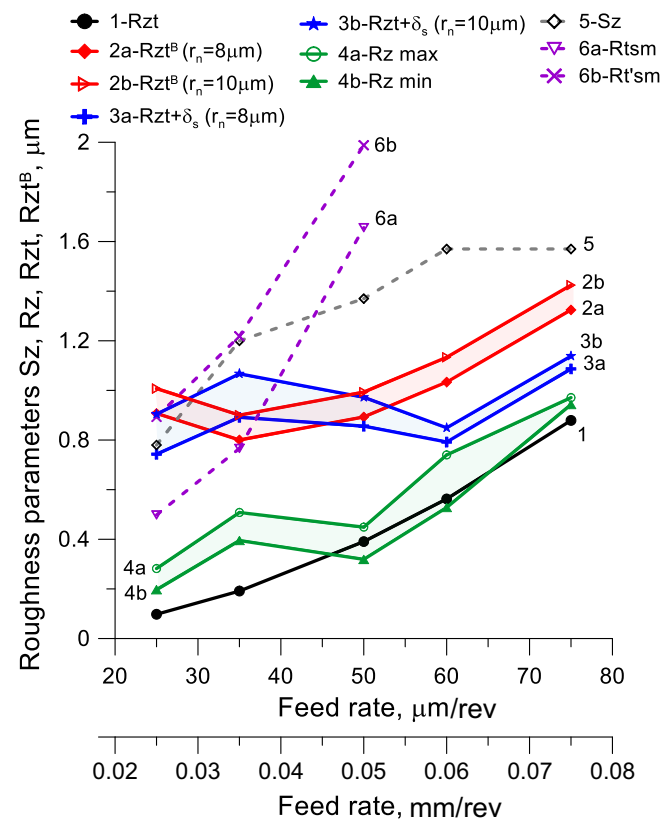

Fig. 4 Possible distortions influencing real surface roughness parameters $2 \mathrm{D}$ and $3 \mathrm{D}$ 


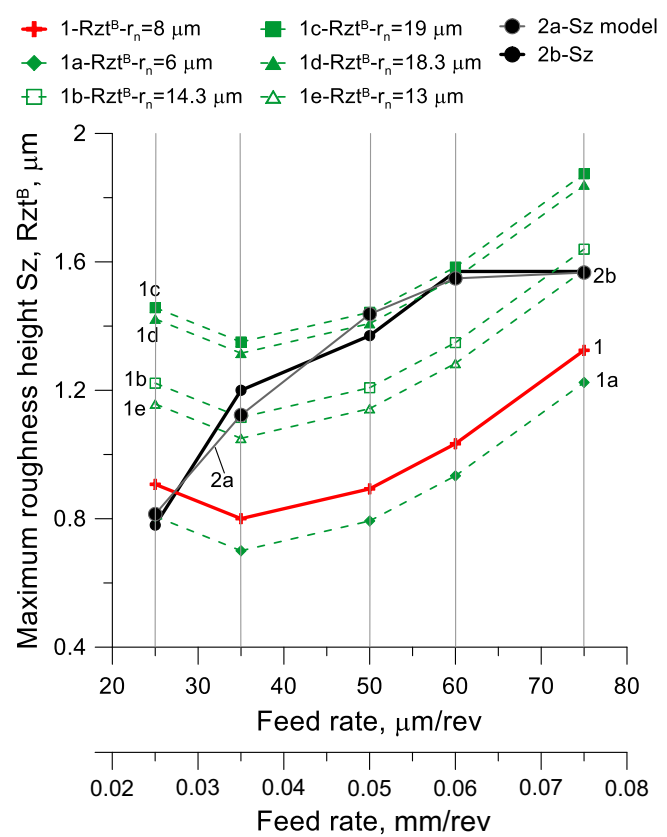

Fig. 5 Fitting of the predicted surface roughness parameter $S z$ to measured data predicted for: $1-\mathrm{r}_{\mathrm{n}}=8 \mu \mathrm{m} ; 1 \mathrm{a}-\mathrm{r}_{\mathrm{n}}=6 \mu \mathrm{m} ; 1 \mathrm{~b}-\mathrm{r}_{\mathrm{n}}=14.3 \mu \mathrm{m} ; 1 \mathrm{c}-$ $\mathrm{r}_{\mathrm{n}}=19 \mu \mathrm{m} ; 1 \mathrm{~d}-\mathrm{r}_{\mathrm{n}}=18.3 \mu \mathrm{m} ; 1 \mathrm{e}-\mathrm{r}_{\mathrm{n}}=13 \mu \mathrm{m} ; 2 \mathrm{a}$ and $2 \mathrm{~b}$-predicted by Eq. 10/measured $S z$ parameter

but its maximum value needs the smoothing and springback effects to be considered (curves \#4a and $4 \mathrm{~b}$ ). In contrast, the $S z$ value is closer to the Brammertz's formula or more accurately to the smoothing effect at the minimum feeds applied.

Figure 5 shows the graphical method for fitting the predicted values of the maximum roughness height to the measured values of $S z$ parameter (curve \#2b). In the first step, the model of the function $S z=\mathrm{f}(f)$ (curve \#2a) was determined using polynomial model in the form of



Fig. 6 Graphical interpretation of Eq. 10. Measured (1) and predicted (2) values of Sz parameter defined in ISO 25178 as the maximum height of the surface
$\mathrm{Sz}=-0.3023+54.545 f-394.97 f$

and using this model, the values of cutting edge radii were computed for all the values of feed rate $(0.025$, $0.035,0.050,0.060$ and $0.075 \mathrm{~mm} / \mathrm{rev}$ ) and constant tool nose radius of $800 \mu \mathrm{m}$. In case of empirical Eq. 10 , the $\mathrm{R}$-squared is equal to $R^{2}=0.9718$ and the residual sum of squares is equal to 0.0122 . It was found that the relevant values of the cutting edge radius which satisfy Eq. 10 are equal to $6,14.3,19$ and $13 \mu \mathrm{m}$, respectively. On the other hand, the next possibility is to change the tool nose radius, i.e. decrease it for lower feeds and increase it for higher feeds.

The measured values and values of the maximum height of the surface Sz predicted by Eq. 10 are presented separately in Fig.6.

\subsection{Analysis of surface topography in terms of constitutive conditions}

Figure 7 shows a series of zoomed surface topographies recorded by means of a confocal 3D profilometer showing characteristic distortion modes obtained at feed rates of $0.025,0.050$ and $0.075 \mathrm{~mm} / \mathrm{rev}$ and additionally, a reference surface topography with regular feed marks generated at the feed of $0.1 \mathrm{~mm} / \mathrm{rev}$. Representative surface textures obtained in PHT operations are labelled by the measured values of 3D roughness parameters. The measured values of $S a$ and $S z$ parameters range from 0.07 to $0.21 \mu \mathrm{m}$ and 0.2 to $1.6 \mu \mathrm{m}$, respectively.

The minimum and maximum values of $R z$ (Fig. 4) determined from two and three automatically selected profiles varied between $0.22-0.95 \mu \mathrm{m}$ and 0.28 $0.97 \mu \mathrm{m}$, respectively. The regular distribution of feed mark characteristic for CBN turned surface with feed rate of $0.1 \mathrm{~mm} / \mathrm{rev}$ is visualized in Fig. $7 \mathrm{~d}$. In Fig. $7 \mathrm{~d}$ also, regular material pile-ups at the secondary cutting (trailing) edge caused by material side flow can be observed. This effect corresponds well quantitatively with FEM predictions made by Kishawy et al. [6] and Schaal et al. [7]. For sharp tools, the maximum springback in metal cutting is equal to $\delta_{s}=0.3-1.6 \mu \mathrm{m}$.

It should be emphasized that plastic side flow results from lateral plastic flow of the material locally heated up to $900-1000{ }^{\circ} \mathrm{C}$ [22]. In addition, associated abrasive wear of the cutting tool is more likely than adhesion [23].

In this study for precision machining it ranges from 0.2 to $0.8 \mu \mathrm{m}$ depending on the ploughing intensity (Fig. 2). On the other hand, the height of lateral flashes resulting from the material side flow which develops at 
a $\mathrm{f}=25 \mu \mathrm{m}, \mathrm{Rt}=0.31 \mu \mathrm{m}, \mathrm{Rz}=0.28 \mu \mathrm{m}, \mathrm{St} / \mathrm{Sz}=0.78 \mu \mathrm{m}$

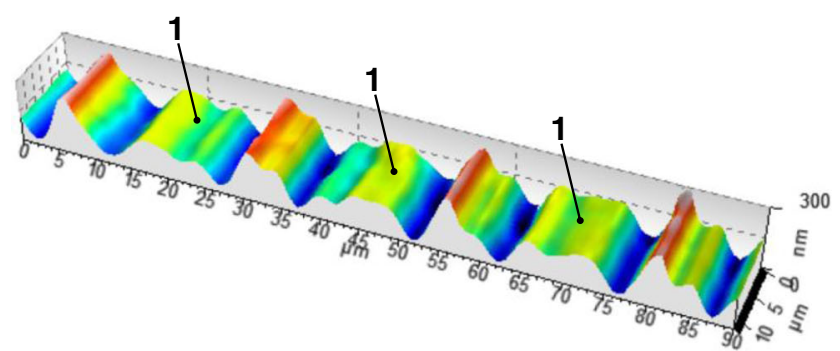

b $\mathrm{f}=50 \mu \mathrm{m}, \mathrm{Rt}=0.52 \mu \mathrm{m}, \mathrm{Rz}=0.45 \mu \mathrm{m}, \mathrm{St} / \mathrm{Sz}=1.37 \mu \mathrm{m}$

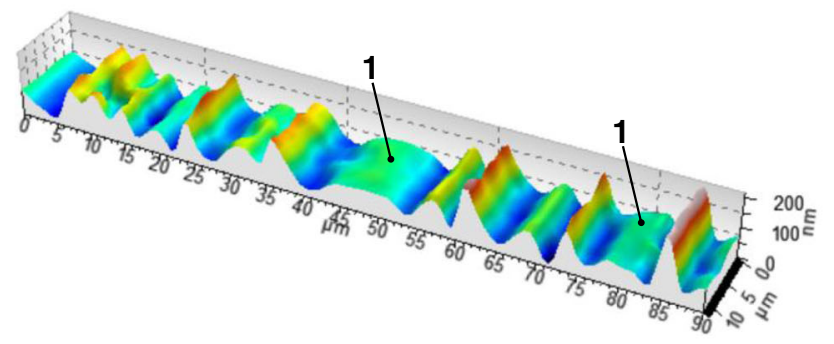

C $f=0.075 \mathrm{~mm} / \mathrm{rev}, R t=0.97 \mu \mathrm{m}, R z=0.97 \mu \mathrm{m}, S t / S z=1.57 \mu \mathrm{m}$

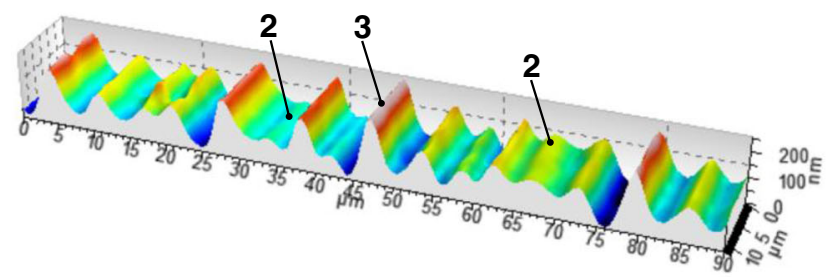

d $f=0.1 \mathrm{~mm} / \mathrm{rev}, R t=1.19 \mu \mathrm{m}, R z=1.13 \mu \mathrm{m}, S t / S z=2.84 \mu \mathrm{m}$

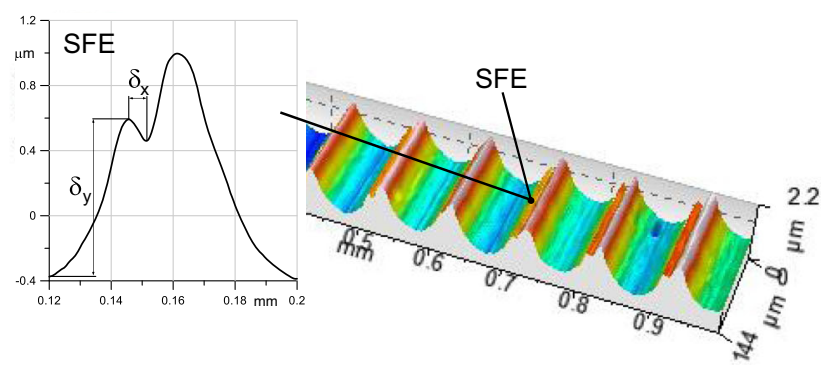

Fig. 7 Characteristic surface topographies obtained at different feeds. a $0.025 \mathrm{~mm} / \mathrm{rev}$. b $0.05 \mathrm{~mm} / \mathrm{rev}$. c $0.075 \mathrm{~mm} / \mathrm{rev}$. d $0.1 \mathrm{~mm} / \mathrm{rev}$. Cutting speed $v_{\mathrm{c}}=150 \mathrm{~m} / \mathrm{min}$, depth of cut $a_{\mathrm{p}}=0.03-0.15 \mathrm{~mm}$. One and two fully and partially smoothed peaks, three full peaks, SFE side flow effect. Magnification $\times 200$ feed of $0.1 \mathrm{~mm} / \mathrm{rev}$ is about $\delta_{y}=1 \mu \mathrm{m}$ as denoted in Fig. 7d. Moreover, the corresponding average nodal displacement is about $\delta_{x}=5 \mu \mathrm{m}$ which coincides with computed data in Ref. [6]. The regular feed marks produced in hard turning operations using low and high feed rates are visualized in Fig. 8. In general, the measured distances between feed marks are practically equal to the nominal values of feed rates selected in this study.

\section{Conclusions}

1. In precision, hard turning performed with $\mathrm{CBN}$ cutting tools and feed rate of $0.025-0.075 \mathrm{~mm} / \mathrm{rev}$ such surface distortion effects as elastic recovery (springback) caused by an intensive ploughing action of the cutting edge, smoothing effect of the generated irregularities in subsequent revolutions and plastic side flow resulting from lateral plastic flow are revealed depending on the feed rate applied.

2. The elastic recovery was established to be mostly predominant at the minimum feeds of 0.025 and $0.035 \mathrm{~mm} / \mathrm{rev}$. The smoothing effect occurring simultaneously with the elastic recovery is also extended to a higher feed of $0.050 \mathrm{~mm} / \mathrm{rev}$.

3. At the feeds of $0.075 \mu \mathrm{m}$ and $0.1 \mathrm{~mm} / \mathrm{rev}$ the minimum uncut chip thickness increases and both these phenomena weaken visibly while surface profiles (topographies) become more regular. Additionally, visible flashes of about $0.6 \mu \mathrm{m}$ in height caused by the side flow effect appear.

4. The three effects were documented quantitatively by the introduction of appropriate analytical models. In particular, in PHT the minimum value of $R z$ parameter is predicted with sufficient accuracy using theoretical formula but its maximum value needs the cutting edge sharpness to be considered. In contrast, the $S z$ values are closer to the Brammertz's formula or more accurately to smoothing effect at the minimum feed rates applied.

5. An original graphical method for fitting the predicted and measured values of the maximum surface height by searching the correct values of the cutting edge radius is proposed. As a result, an empirical model for prediction of
Fig. 8 Optical images of surface topographies obtained at low (a) $0.025 \mathrm{~mm} / \mathrm{rev}$ and high $(\mathbf{b})$ $0.075 \mathrm{~mm} / \mathrm{rev}$ feeds at magnification $\times 200$
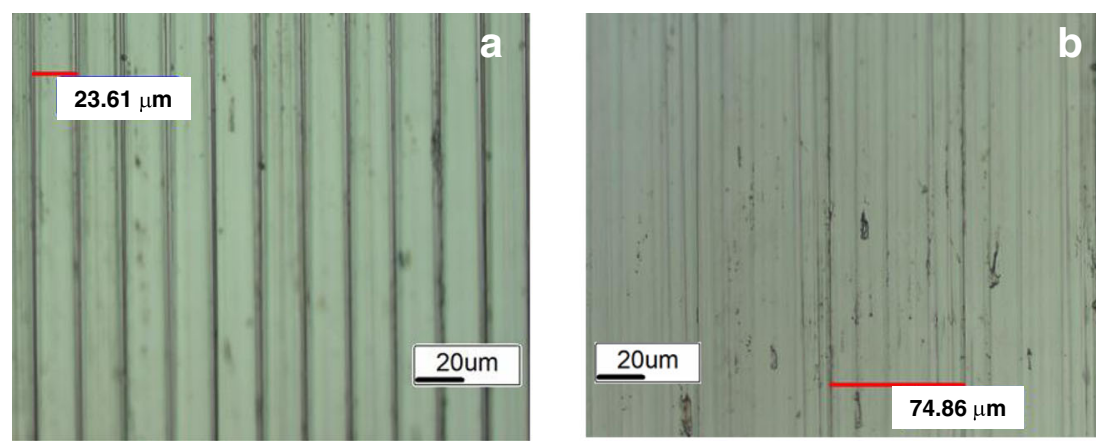
the Sz parameter in terms of the feed rate used is derived. Moreover, the possible distortions of the machined surface topographies are visualized in the form of isometric views.

6. Future trends can be focussed on experimental investigations in micro-scale using specially designed devices and accurate FEM-based modelling of surface generation mechanisms including associated distortion effects. It is also important to design cutting tools with precisely prepared cutting edges, keeping the recommended cutting edge radius and the tool corner radius. It is also plausible to extend this analysis to higher tool corner radiuses, i.e. $1.2,1.6$ or $2.4 \mathrm{~mm}$.

\section{Nomenclature}

$a_{\mathrm{p}} \quad$ depth of cut

$b_{\gamma} \quad$ chamfer width

$b_{\alpha} \quad$ land width at the flank face

$e_{\mathrm{c}} \quad$ specific cutting energy

$e_{\mathrm{p}} \quad$ specific ploughing energy

$f \quad$ feed rate

$h_{\min } \quad$ minimum uncut chip thickness

$h_{\mathrm{m}} \quad$ average uncut chip thickness

$l_{\underline{\mathrm{k}}} \quad$ length of the equivalent cutting edge

$r_{\mathrm{n}} \quad$ radius of the cutting edge

$r_{\varepsilon} \quad$ radius of tool corner

$v_{\mathrm{c}} \quad$ cutting speed

$A_{\mathrm{c}} \quad$ cross-sectional area of cut

$F_{\mathrm{c}} \quad$ cutting force

$F_{\mathrm{f}} \quad$ feed force

$F_{\mathrm{p}} \quad$ passive force

$F_{1} \quad$ force parallel to the cutting edge

$F_{\mathrm{m}} \quad$ force perpendicular to the rake face

$F_{n} \quad$ force parallel to the rake face
$F_{\gamma} \quad$ friction force

$F_{\gamma \mathrm{N}} \quad$ normal force on the rake face

$R a \quad$ average value of surface roughness

$R z \quad$ maximum roughness height

$R z t \quad$ theoretical value of Rz parameter

$R z t^{B} \quad$ theoretical value of Rz parameter predicted by Brammertz's model

$\mathrm{Sa}$ arithmetic mean height of the surface

$S z \quad$ ten point height of the surface

St total height of the surface

$\gamma_{\mathrm{n}} \quad$ normal rake angle

$\gamma_{\text {nc }} \quad$ chamfer angle

$\lambda_{\mathrm{s}} \quad$ tool inclination angle

$\mu_{\gamma} \quad$ friction coefficient at the rake face

$\delta_{\mathrm{s}} \quad$ springback value

$\delta_{\mathrm{x}} \quad$ nodal displacement of the peak

$\delta_{\mathrm{y}} \quad$ height of a pile-up

\section{Abbreviations}

CBN cubic boron nitride

FEM finite element method

HPT high precision turning

PCD polycrystalline diamond

HPM high precision machining

SFE side flow effect

TM transformation matrix

UCT uncut chip thickness 


\section{Appendix}

Table 1 Values of cutting forces, specific ploughing energy, friction coefficient and elastic recovery

\begin{tabular}{|c|c|c|c|c|c|c|c|}
\hline Feed, $f(\mathrm{~mm} / \mathrm{rev})$ & $\begin{array}{l}\text { Force } \\
F_{\mathrm{c}}\left(F_{\mathrm{z}}\right) \\
N\end{array}$ & $\begin{array}{l}\text { Force } \\
F_{\mathrm{p}}\left(F_{\mathrm{y}}\right) \\
N\end{array}$ & $\begin{array}{l}\text { Force } \\
F_{\mathrm{f}}\left(F_{\mathrm{x}}\right) \\
N\end{array}$ & $\begin{array}{l}\text { Specific energy } \\
e_{\mathrm{p}} \\
\left(\mathrm{GJ} / \mathrm{m}^{3}\right)\end{array}$ & $\begin{array}{l}\text { Friction coefficient } \\
\mu_{\gamma \mathrm{n}}\end{array}$ & $\begin{array}{l}\text { Elastic recovery } \\
\delta_{\mathrm{s}}\left(r_{\mathrm{n}}=8 \mu \mathrm{m}\right) \\
(\mu \mathrm{m})\end{array}$ & $\begin{array}{l}\text { Elastic recovery } \\
\delta_{\mathrm{s}}\left(\mathrm{r}_{\mathrm{n}}=10 \mu \mathrm{m}\right) \\
(\mu \mathrm{m})\end{array}$ \\
\hline 0.025 & 13.20 & 32.30 & 3.70 & 24.86 & 2.63 & 0.70 & 0.81 \\
\hline 0.035 & 17.10 & 43.50 & 8.00 & 43.07 & 2.50 & 0.65 & 0.88 \\
\hline 0.05 & 26.00 & 54.10 & 9.90 & 21.64 & 2.11 & 0.47 & 0.58 \\
\hline 0.06 & 64.90 & 113.00 & 36.40 & 12.56 & 1.65 & 0.23 & 0.29 \\
\hline 0.075 & 77.20 & 131.20 & 41.80 & 11.66 & 1.61 & 0.21 & 0.26 \\
\hline
\end{tabular}

Table 2 Values of measured and computed surface roughness parameters

\begin{tabular}{llllllll}
\hline $\begin{array}{l}\text { Feed, } f \\
(\mathrm{~mm} / \mathrm{rev})\end{array}$ & $\begin{array}{l}S a \\
(\mu \mathrm{m})\end{array}$ & $\begin{array}{l}R a, \\
(\mu \mathrm{m})\end{array}$ & $\begin{array}{l}S z \\
(\mu \mathrm{m})\end{array}$ & $\begin{array}{l}R z_{\max }, \\
(\mu \mathrm{m})\end{array}$ & $\begin{array}{l}R z_{\min }, \\
(\mu \mathrm{m})\end{array}$ & $\begin{array}{l}R_{\mathrm{zt}} \\
(\mu \mathrm{m})\end{array}$ & $\begin{array}{l}R_{\mathrm{t}}^{B} \\
(\mu \mathrm{m})\end{array}$ \\
\hline 0.025 & 0.07 & 0.04 & 0.78 & 0.282 & 0.197 & 0.10 & 1.01 \\
0.035 & 0.138 & 0.065 & 1.20 & 0.508 & 0.395 & 0.19 & 0.90 \\
0.05 & 0.14 & 0.07 & 1.37 & 0.449 & 0.319 & 0.39 & 0.99 \\
0.06 & 0.21 & 0.13 & 1.57 & 0.740 & 0.528 & 0.56 & 1.13 \\
0.075 & 0.28 & 0.26 & 1.57 & 0.971 & 0.943 & 0.88 & 1.42 \\
\hline
\end{tabular}

Open Access This article is distributed under the terms of the Creative Commons Attribution 4.0 International License (http:// creativecommons.org/licenses/by/4.0/), which permits unrestricted use, distribution, and reproduction in any medium, provided you give appropriate credit to the original author(s) and the source, provide a link to the Creative Commons license, and indicate if changes were made.

\section{References}

1. Davim JP (ed) (2011) Machining of hard materials. Springer, Berlin

2. Grzesik W (2017) Advanced machining processes of metallic materials. Elsevier, Amsterdam

3. Grzesik W (1996) A revised model for predicting surface roughness in turning. Wear 194:143-148

4. Knueferman MMW, McKeown PA (2004) A model for surface roughness in ultraprecision hard turning. Ann CIRP 53:99-102

5. Childs THC, Sekiya K, Tezuka R, Yamane Y, Dornfeld D, Lee DE, Min S, Wright PK (2008) Surface finishes from turning and facing with round nosed tools. Ann CIRP Manuf Technol 57:89-92

6. Kishawy HA, Haglund A, Balazinski M (2006) Modelling of material side flow in hard turning. Ann CIRP Manuf Technol 55:8588

7. Chen T, Qiu C, Liu X (2017) Study on 3D topography of machined surface in high-speed hard cutting with PCBN tool. Int J Adv Manuf Technol 91:2125-2133
8. Schaal N, Kuster F, Wegener K (2015) Springback in metal cutting with high cutting speeds. Proc CIRP 31:24-28

9. Benardos PG, Vosniakos G-C (2003) Predicting surface roughness in machining: a review. Int J Mach Tools Manuf 43:833-844

10. Jiang XJ, Whitehouse DJ (2012) Technological shifts in surface metrology. Ann CIRP Manuf Technol 61:815-836

11. Ozel T, Hsu T-K, Zeren E (2005) Effects of cutting geometry, workpiece hardness, feed rate and cutting speed on the surface roughness and forces in finish turning of hardened AISI H13 steel. Int J Adv Manuf Technol 25:262-269

12. Grzesik W, Rech J, Żak K (2014) Determination of friction in metal cutting with tool wear and flank face effects. Wear 317:8-16

13. Grzesik W, Denkena B, Żak K, Grove T, Bergman B (2015) Energy consumption characterization in precision hard machining using CBN cutting tools. Int J Adv Manuf Technol 85:2839-2845

14. Pawlus P, Wieczorowski M, Mathia T (2014) The errors of stylus methods in surface topography measurements. Zapol Publ, Szczecin

15. Leach R (ed) (2013) Characterisation of areal surface texture. Springer, Berlin

16. W. Grzesik (2010) Generation and modelling of surface roughness in machining using geometrically defined cutting tools. In: Metal cutting. Research Advances, Nova Science Publishers, Chapter 6, New York 163-185

17. Zheleznov GS, Singeev SA (1983) Calculation of forces acting on the tool flank face (in Russian). Izvestija VUZ Mashinostroenie 9: 146-148

18. Yuan ZJ, Zhou M, Dong S (1996) Effects of diamond tool sharpness on the minimum cutting thickness and cutting surface integrity in ultraprecision machining. J Mat Proc Technol 62:327-330

19. Grzesik W (2010) Fundamentals of machining of construction materials. WNT (in Polish), Warsaw

20. Miko E (2005) Generation of micro-irregularities on metallic surfaces machined with cutting tools with defined geometry (in Polish), Scientific Monograph No. 46. Publishing House of Kielce University of Technology, Kielce

21. Denkena B, Biermann D (2014) Cutting edge geometries. Ann CIRP Manuf Technol 63:631-653

22. Wang JY, Liu CR (1999) The effect of tool flank wear on the heat transfer, thermal damage and cutting mechanics in finish hard turning. Ann CIRP 48:53-58

23. Chinchanikar S, Choudhury SK (2015) Machining of hardened steel-experimental investigations, performance modelling and cooling techniques: a review. Int J Mach Tools Manuf 89:95-109 